\title{
O FEDERALISMO BRASILEIRO E OS PLANOS DE ABERTURA ECONÔMICA DO ESTADO DE ALAGOAS E SÃO PAULO PARA A PANDEMIA DA COVID-19
}

\author{
EL FEDERALISMO BRASILEÑO Y LOS PLANES DE APERTURA ECONÓMICA DEL \\ ESTADO DE ALAGOAS Y SAO PAULO PARA LA PANDEMIA DE COVID-19
}

\author{
BRAZILIAN FEDERALISM AND THE ECONOMIC OPENING PLANS OF THE \\ STATE OF ALAGOAS AND SÃO PAULO FOR THE COVID-19 PANDEMIC
}

\author{
Raissa Giacon Escarelli ANDRADE ${ }^{1}$ \\ Igor Copoli RAMAZZINE ${ }^{2}$ \\ Luciléia Aparecida COLOMBO ${ }^{3}$
}

RESUMO: A pandemia da Covid-19 tem abalado o mundo nos diversos setores políticos, sociais e econômicos, desafiando os gestores, bem como a própria administração pública, na busca de soluções rápidas e eficientes, mas não planejadas, dado o momento inusitado em que vivemos. O Brasil não foge desse caminho, tendo o seu federalismo posto em cheque pelo momento vivido, acentuado por uma forte crise política. Nesse sentido, nos cabe entender como os estados têm agido para realizar a reabertura dos setores comerciais e industriais, mais especificamente São Paulo e Alagoas. O artigo sugere que os planos de reabertura econômica estão intrinsecamente ligados ao modelo de federalismo que o Brasil adotou, ora centralizado, ora descentralizado, mas promovendo mecanismos que permitem a articulação de seus entes federados. Os planos de abertura econômica são documentos importantes neste momento póspandemia, pois regulam os indivíduos, o setor do comércio e da indústria, elementos chave para a geração de empregos no país.

PALAVRAS-CHAVE: Covid-19. Federalismo. Retomada econômica. Alagoas. São Paulo.

RESUMEN: La pandemia de Covid-19 ha sacudido al mundo en los diversos sectores políticos, sociales y económicos, desafiando a los gestores, así como a la propia administración pública, en la búsqueda de soluciones rápidas y eficientes, pero no planificadas, dado el momento inusual en que vivimos. En Brasil no es distinto, pues su federalismo ha sido desafiado en el momento vivido, acentuado por una fuerte crisis politica. En ese sentido, tenemos que entender cómo los estados han actuado para realizar la reapertura de los sectores comerciales e industriales, más específicamente São Paulo y Alagoas. El artículo sugiere que los planes de reapertura económica están intrínsecamente ligados al modelo de federalismo que Brasil ha adoptado, ya sea centralizado o descentralizado, pero promoviendo mecanismos que permiten

${ }^{1}$ Universidade Estadual Paulista (UNESP), Araraquara - SP - Brasil. Graduanda em Ciências Sociais. Membro do Grupo de Estudo e Pesquisa Participação e Democracia - GEPPADE. ORCID: https://orcid.org/0000-00020346-1609. E-mail: raissa.escarelli@hotmail.com

${ }^{2}$ Universidade Estadual Paulista (UNESP), Araraquara - SP - Brasil. Graduando em Ciências Sociais. Membro do Grupo de Estudo e Pesquisa Participação e Democracia - GEPPADE. Bolsista Fapesp. ORCID: https://orcid.org/0000-0002-4402-3197. E-mail: igor.copoli567@gmail.com

${ }^{3}$ Universidade Federal de Alagoas (UFAL), Maceió - AL - Brasil. Professora Adjunta do Instituto de Ciências Sociais. Doutorado em Ciência Política (UFSCAR). ORCID: https://orcid.org/0000-0002-5285-4716. E-mail: leiacolombo@gmail.com 
la articulación de sus entes federados. Los planes de apertura económica son documentos importantes en este momento post-pandemia, pues regulan a los individuos, al sector del comercio y de la industria, elementos estos claves para la generación de empleos en el país.

PALABRAS CLAVE: Covid-19. Federalismo. Recuperación Económica. Alagoas. São Paulo.

ABSTRACT: The Covid-19 pandemic has shaken the world in different political, social and economic sectors, challenging managers, as well as the public administration itself, in the search for quick and efficient solutions, but not planned, given the unusual moment in which we live. Brazil does not escape this path, having its federalism put in check due to the moment lived, aggravated by a strong political crisis. In this sense, it is up to us to understand how the states have acted to reopen the commercial and industrial sectors, more specifically São Paulo and Alagoas. The article suggests that the plans for economic reopening are intrinsically linked to the model offederalism that Brazil adopted, sometimes centralized, sometimes decentralized, but promoting mechanisms that allow the articulation of its federated entities. Economic opening plans are important documents in this post-pandemic moment, as they regulate individuals, and trade and industry sectors, key elements for the generation of jobs in the country.

KEYWORDS: Covid-19. Federalism. Economic recovery. Alagoas. São Paulo.

\section{Introdução}

A pandemia da Covid-19 impôs alguns desafios ao federalismo brasileiro, cuja principal característica é a diferença regional observada no tocante às regiões nordeste e sudeste. Neste sentido, o presente estudo propõe uma análise dos planos de abertura econômica dos estados de Alagoas e São Paulo, considerando que após a fase do isolamento social, os governadores adotam medidas sanitárias e protocolos para nortear a abertura gradual do comércio e da indústria. Nossa intenção é expressar, por meio dos dois planos, a posição dos respectivos estados no enfrentamento da crise sanitária e econômica, descortinando os limites do federalismo brasileiro. Como objetivo secundário, buscaremos comparar os dois planos, procurando semelhanças e diferenças entre eles; adotamos uma metodologia de fonte primária, focada na análise destes documentos e portarias emitidos pelos estados.

Este estudo justifica-se por dois conjuntos de razões. O primeiro deles é que a pandemia trouxe à luz o debate sobre o papel dos entes federados. O caráter inusitado da Covid-19 e as urgentes tomadas de decisão que a doença impõe estão colocando à prova o federalismo brasileiro. Pretendemos contribuir com a agenda de estudos sobre o federalismo, mostrando como a pandemia promoveu mudanças substanciais na economia, na política e na relação entre os entes federados no Brasil. Além disso, justifica-se pela comparação inédita entre dois planos 
de governos para enfrentamento da crise, sendo eles dos estados de São Paulo (Região Sudeste) e Alagoas (Região Nordeste). Assim, nosso trabalho poderá incitar novos estudos comparativos que ilustrem as diferenças dos entes federados na tomada de decisão frente às crises sanitária, econômica e política.

Além desta introdução, o artigo tem mais quatro seções. Na próxima, fará um breve histórico sobre o federalismo brasileiro. Na terceira, trará dados sobre o Plano de Alagoas. Na quarta, traremos os dados sobre o Plano São Paulo. A última seção se dedicará a fazer algumas considerações finais.

\section{O federalismo brasileiro - algumas características:}

O federalismo brasileiro possui algumas características que lhe são peculiares. Em primeiro lugar, com a Constituição de 1988, houve um grande processo de descentralização, tanto de recursos financeiros como de poder aos entes subnacionais. Esta novidade constitucional foi confundida com a democratização, pois o contexto demarcava o fim do período autoritário brasileiro, que durou 21 anos. Como salienta Arretche (1996):

A partir de perspectivas políticas distintas se produziu um grande consenso em torno da descentralização. Passou-se a supor que, por definição, formas descentralizadas de prestação de serviços públicos seriam mais democráticas e que, além disso, fortaleceriam e consolidariam a democracia. Igualmente, tal consenso supunha que formas descentralizadas de prestação de serviços públicos seriam mais eficientes e que, portanto, elevariam os níveis reais de bem-estar da população. Portanto, reformas do Estado nessa direção seriam desejáveis, dado que viabilizariam a concretização de ideais progressistas, tais como equidade, justiça social, redução do clientelismo e aumento do controle social sobre o Estado. Simetricamente, passou-se a associar centralização a práticas não democráticas de decisão, à ausência de transparência das decisões, à impossibilidade de controle sobre as ações de governo e à ineficácia das políticas públicas. As expectativas postas sobre a descentralização e a visão negativa das formas centralizadas de gestão implicariam, como consequência, a necessária redução do escopo de atuação das instâncias centrais de governo (ARRETCHE, 1996, p. 1).

Neste sentido, a literatura de federalismo aponta diversos modelos, com arranjos entre os entes federados com mais ou menos autonomia, mas todos com a prerrogativa de manter a unidade na diversidade. Quanto às relações intergovernamentais, algumas considerações de Souza (2019) merecem destaque:

O federalismo brasileiro redesenhado em 1988 gerou interpretações divergentes. Uns concluíram que a federação era dominada por interesses estaduais, pelo poder informal que poderia ser exercido pelos governadores 
sobre os parlamentares de seus estados no Congresso Nacional. Essa tese teve grande influência na interpretação do funcionamento do federalismo no Brasil, sendo também partilhada por vários cientistas políticos norteamericanos. Outra corrente analisou a divisão de poder dentro da federação como fragmentada entre vários centros de poder, embora com capacidades desiguais, ou seja, não haveria o comando de apenas uma ou de poucas unidades constitutivas da federação. A despeito da centralização legislativa, de recursos financeiros e de formulação de políticas, os governos subnacionais não são atores passivos no jogo federativo (SOUZA, 2019, p. 2).

Para a compreensão do federalismo, é importante observar três questões básicas: a primeira, entender a motivação para que populações e sociedades de regiões diferentes, com características particulares, abdicam de suas autonomias para formarem um pacto, que limitará a sua autonomia? Além disso, quais as vantagens para estarem unidos neste pacto? E, finalmente, como pensar em mecanismos coordenados para que os entes federados possam obter articulação entre si?

Autores como Riker (1964) defendem o federalismo por conta de uma dimensão protetiva, ou seja, um sistema que auxilia na proteção contra ofensivas militares, além de proteger economicamente os entes subnacionais de contratos mal elaborados ou de trocas financeiras mal sucedidas. Para este autor, o federalismo possui a vantagem de determinar as prerrogativas de cada ente federado, no sistema conhecido como checks and balances (pesos e contrafreios), através do qual as unidades federadas controlam-se, estimulando a autonomia entre elas, estimulando a cooperação e a confiança mútua.

Além disso, a ideia dos checks and balances está intimamente ligada a união na diversidade (ELAZAR, 1984), definida como um sistema de decisão coletiva, definido por uma Constituição Federal, responsável por regular o desenho das políticas públicas que serão implementadas, a partir da articulação entre os seus entes. Neste sentido, a partir da clara conceituação do federalismo, podemos observar a relação deste com as formas intergovernamentais e de que maneira os serviços públicos são ofertados.

Um ponto decisivo no federalismo brasileiro é a grande desigualdade regional observada principalmente no Nordeste em relação às demais, visto que os níveis de desigualdade são bem acentuados, especialmente quando observamos estados como Alagoas, Bahia, Ceará, Maranhão, Paraíba, Pernambuco, Piaú́, Rio Grande do Norte e Sergipe em relação a São Paulo, por exemplo, conforme podemos observar no quadro abaixo: 
Quadro 1 - Índice de Emprego e Renda - Estados Brasileiros - 2000 a 2010

\begin{tabular}{|c|c|c|c|c|c|c|c|}
\hline Estado & 2000 & 2005 & 2006 & 2007 & 2008 & 2009 & 2010 \\
\hline Acre & 0,4865 & 0,5290 & 0,5799 & 0,5612 & 0,5198 & 0,5199 & 0,5687 \\
\hline Alagoas & 0,4639 & 0,5078 & 0,5074 & 0,4456 & 0,4609 & 0,4689 & 0,4402 \\
\hline Amazonas & 0,4741 & 0,6130 & 0,6602 & 0,6312 & 0,6277 & 0,5068 & 0,5430 \\
\hline Amapá & 0,4335 & 0,4960 & 0,5900 & 0,5478 & 0,5871 & 0,5377 & 0,5628 \\
\hline Bahia & 0,5288 & 0,7356 & 0,6512 & 0,6488 & 0,6387 & 0,6947 & 0,7292 \\
\hline Ceará & 0,4940 & 0,5627 & 0,5772 & 0,5562 & 0,5817 & 0,6430 & 0,6645 \\
\hline Distrito Federal & 0,5084 & 0,6357 & 0,6342 & 0,5913 & 0,6433 & 0,6153 & 0,6112 \\
\hline Espírito Santo & 0,4735 & 0,7151 & 0,7107 & 0,6664 & 0,6607 & 0,6070 & 0,6357 \\
\hline Goiás & 0,4978 & 0,6465 & 0,6164 & 0,6347 & 0,6304 & 0,6356 & 0,6757 \\
\hline Maranhão & 0,4510 & 0,4161 & 0,5190 & 0,5334 & 0,5632 & 0,4879 & 0,5563 \\
\hline Minas Gerais & 0,5209 & 0,8159 & 0,8696 & 0,8289 & 0,8509 & 0,7827 & 0,8256 \\
\hline Mato Grosso do Sul & 0,4453 & 0,6114 & 0,5940 & 0,5433 & 0,5932 & 0,5932 & 0,5998 \\
\hline Mato Grosso & 0,4259 & 0,5558 & 0,5667 & 0,5598 & 0,6032 & 0,5728 & 0,5902 \\
\hline Pará & 0,4819 & 0,5750 & 0,6116 & 0,6155 & 0,5809 & 0,5164 & 0,5998 \\
\hline Paraíba & 0,4811 & 0,4889 & 0,5056 & 0,4724 & 0,4566 & 0,4937 & 0,5352 \\
\hline Pernambuco & 0,5459 & 0,6030 & 0,6216 & 0,6132 & 0,6577 & 0,6428 & 0,7463 \\
\hline Piauí & 0,4442 & 0,4625 & 0,5064 & 0,4720 & 0,5334 & 0,5375 & 0,5403 \\
\hline Paraná & 0,4753 & 0,8209 & 0,8344 & 0,8427 & 0,8641 & 0,8022 & 0,8376 \\
\hline Rio de Janeiro & 0,5619 & 0,8058 & 0,8872 & 0,8810 & 0,9027 & 0,8541 & 0,8745 \\
\hline Rio Grande do Norte & 0,4663 & 0,5676 & 0,5714 & 0,5442 & 0,5596 & 0,5224 & 0,5631 \\
\hline Rondônia & 0,5314 & 0,5409 & 0,5999 & 0,5251 & 0,5538 & 0,6812 & 0,6901 \\
\hline Roraima & 0,4121 & 0,5971 & 0,5964 & 0,5653 & 0,4777 & 0,5882 & 0,5435 \\
\hline Rio Grande do Sul & 0,5255 & 0,6885 & 0,7362 & 0,7430 & 0,7927 & 0,7496 & 0,8317 \\
\hline Santa Catarina & 0,4891 & 0,7708 & 0,7983 & 0,7588 & 0,7719 & 0,7149 & 0,7846 \\
\hline Sergipe & 0,4541 & 0,6060 & 0,6089 & 0,5365 & 0,5883 & 0,6005 & 0,6433 \\
\hline São Paulo & 0,5937 & 0,8379 & 0,8890 & 0,8695 & 0,8900 & 0,8688 & 0,8843 \\
\hline Tocantins & 0,4166 & 0,5531 & 0,5477 & 0,5625 & 0,5101 & 0,5415 & 0,5456 \\
\hline
\end{tabular}

Fonte: Desenvolvido com dados exclusivamente obtidos da Plataforma IPEADATA (2020).

A observação de tais assimetrias é a justificativa do presente estudo, que pretende analisar os estados de Alagoas e São Paulo no tocante aos planos de abertura econômica, 
necessários para organizar o trânsito de pessoas na pandemia. Ademais, é preciso ressaltar que no momento da pandemia de Covid-19 no Brasil, os estados e seus governadores foram os grandes protagonistas nas medidas de isolamento social e, mais recentemente, nos planos de abertura econômica, com a publicação de decretos de medidas sanitárias para os seus cidadãos. Diante da ausência de registros deste momento específico, consideramos adequado a análise de dois planos de abertura econômica, para os estados de São Paulo e de Alagoas. Este artigo está dividido da seguinte forma: esta introdução, seguida de um item sobre o plano de Alagoas para a retomada econômica, posteriormente, uma análise do plano São Paulo de abertura das atividades produtivas, seguido de um item sobre a comparação dos dois planos e, finalmente, uma conclusão. Feitas estas considerações iniciais, passamos então para os itens aqui dispostos.

\section{Plano Alagoas de retomada econômica}

O Estado de Alagoas iniciou o enfrentamento à pandemia do coronavírus no dia 8 de março de 2020, mas somente no dia 23 do mesmo mês teve a confirmação de seu primeiro caso de transmissão comunitária, e a primeira morte causada pela doença se deu no dia 31 de março. No entanto, a grande expansão de casos se deu a partir do final do mês de abril e foi a capital, Maceió, que concentrou o maior número de casos.

A resposta dada pelo governo do estado foi rápida, uma vez que 5 dias após a confirmação de seu primeiro caso, foi feito o primeiro decreto pelo governador Renan Filho (MDB) - Decreto ${ }^{\circ}$ 69.501, de 13 de março de 2020 - o qual trouxe as primeiras medidas para o combate à pandemia, como: isolamento social, quarentena, exames médicos, testes laboratoriais, entre outras. Desde o primeiro decreto, foram editados mais oito, quase sempre reeditando as medidas de isolamento. Cabe ressaltar que as medidas tomadas levaram em conta instruções do comitê científico criado pelo Consórcio Nordeste, no entanto, os baixos índices de isolamento social acabaram contribuindo para o vírus.

O Consórcio Nordeste tem como base a Lei $\mathrm{n}^{\mathrm{o}}$ 11.107, de 6 de abril de 2005, que "constituiu uma das primeiras iniciativas do Estado brasileiro a colocar na agenda pública a possibilidade de efetivação de 'pactos territoriais' que facilitem as relações intergovernamentais" (CLEMENTINO, 2019, p. 166), possibilitando então sua criação, a qual se deu no ano de 2019, com o objetivo de integrar a região, possibilitando o desenvolvimento social e econômico; elegendo como áreas prioritárias de atuação a saúde, segurança pública e educação, contando também com compras coletivas visando aprimoramento da gestão pública. São prioridades que se tornam ainda mais importantes no período da pandemia do Covid-19, e 
que tornam crucial a participação do consórcio na região. Acerca da organização cabe colocar que fora construída com base em discordâncias políticas da região com o governo federal, se tornando uma ferramenta de fortalecimento regional, tornando sólidas as relações intergovernamentais e seus posicionamentos políticos frente ao federal.

No dia 22 de junho de 2020 foi editado, então, o decreto $n^{\circ} 70.145$, que demarca o início do plano de retomada econômica de Alagoas, chamado Plano de Distanciamento Controlado. O documento elaborado pelo grupo de trabalho do Governo de Alagoas, conduzido pelo Gabinete Civil e Secretarias de Desenvolvimento Econômico e Turismo (SEDETUR) e da Fazenda (SEFAZ), de forma conjunta com setores produtivos, representantes de sindicatos do Estado e membros da sociedade civil, define cinco fases classificadas por cores: vermelha, laranja, amarela, azul e verde; que vão de um risco mais alto para um mais controlado. Para complementar o Plano, uma matriz de risco foi publicada pelo decreto $\mathrm{n}^{0} 70.177$, no dia 26 de junho, que especifica como serão os indicadores para que se demarque os avanços ou retrocessos nas fases.

O plano de retomada econômica conta com uma descrição detalhada de quais estabelecimentos podem ser abertos nas diferentes fases e o modo como devem operar. Além disso, o documento estabelece minuciosamente os procedimentos de segurança sanitária - uso de máscaras, álcool gel, controle do fluxo de pessoas, "drive thru”, aumento da frequência de limpeza e outros - que devem ser seguidos para o funcionamento dos locais que serão reabertos em cada fase. Ainda há de se ressaltar que existem também indicações sanitárias para espaços específicos, como templos religiosos.

Para pôr em prática o Plano de Distanciamento Controlado, foi estipulado pelo decreto três eixos estratégicos: utilização da capacidade hospitalar instalada, que é composto por 3 indicadores: taxa de ocupação de leitos com respiradores, taxa de ocupação de leitos em geral e quantidade de leitos com respiradores por 100 mil habitantes; evolução epidemiológica que possui dois indicadores: óbitos por semana epidemiológica e taxa de letalidade, e taxa de evolução da Covid-19 que conta com um indicador - razão de casos ativos por casos recuperados.

No dia 30 de junho foi editado um terceiro decreto acerca do tema da retomada econômica, o decreto $\mathrm{n}^{0} 70.178$, que se aproxima um pouco do modelo aplicado no Estado de São Paulo, ao dividir o Estado, aplicando de maneira territorializada a flexibilização; com isso a capital entrou na fase laranja e os municípios do interior na fase vermelha. A partir do dia 20 de julho Maceió entrou na fase amarela, além de alguns municípios da região metropolitana e do litoral norte irem para a fase amarela. 


\section{Plano São Paulo de retomada econômica}

O Estado de São Paulo foi o primeiro a criar um centro de contingência para combater a pandemia do novo Covid-19. O primeiro caso confirmado de infecção data do dia 26 de fevereiro, e no dia 15 de março a primeira morte foi confirmada. No dia 16 de março, o decreto n 64.864 instituiu o Comitê Administrativo Extraordinário Covid-19 com a responsabilidade para deliberar sobre casos adicionais abrangidos pela medida de quarentena. Formulado com o apoio deste mesmo Comitê, o decreto $n^{0} 64.881$ determinou quarentena no Estado de São Paulo e restrição de atividades de maneira a evitar possível contaminação ou propagação do vírus.

É interessante pontuar que tal decreto foi publicado 49 dias depois da Portaria MS n ${ }^{\circ}$ 188, de 3 de fevereiro de 2020, na qual o Ministro da Saúde declarou Emergência em Saúde Pública de Importância Nacional (ESPIN) em decorrência da Infecção Humana pelo Novo Coronavírus, e 6 dias depois do primeiro caso confirmado.

O decreto de quarentena estabeleceu o fim do atendimento presencial ao público em estabelecimentos comerciais e prestadores de serviços, especialmente em casas noturnas, shopping centers, galerias, academias e centros de ginástica. Permaneceram em funcionamento apenas os serviços essenciais como hospitais, farmácias, mercados, postos de combustível e serviços de segurança. Tais medidas foram efetivadas no dia seguinte da publicação, 24 de março.

Após 64 dias da medida de quarentena, entre outros decretos que auxiliaram na contingência do Covid-19 e amparo a população, o Governo, juntamente com a Secretaria da Saúde, entendeu que o combate à pandemia havia entrado em uma nova fase no Estado. Foi fundamental a adoção de medidas de distanciamento social para desacelerar a curva epidemiológica e permitir o planejamento e a execução de ações para o incremento da capacidade hospitalar da rede pública de saúde. Também foi importante porque permitiu ao Centro de Contingência avaliar a dinâmica da transmissão da doença no território do Estado.

Há o entendimento que o Estado de São Paulo possui especificidades regionais que devem ser respeitadas, sendo assim, uma nova proposta de quarentena é aplicada, de maneira que organize cada região de acordo com a abrangência dos Departamentos Regionais de Saúde (DRS) e as Redes Regionais de Atenção à Saúde (RRAS), e observada por meio do Sistema de Informação e Monitoramento Inteligente (SIMI - instituído pelo decreto $n^{\circ} 64.963$, de 5 de maio de 2020). A quarentena que antes era homogênea por todo o Estado, passou a ser heterogênea, respeitando as particularidades de cada setor de acordo com um plano de 
retomada. Sendo assim, a aplicação das medidas que o plano propõe, que serão detalhadas à frente, é diferente e direcionada para cada área do Estado de acordo com a divisão administrativa da Secretaria de Estado, que dividiu as regiões em 17 Departamentos de Saúde, responsáveis por coordenar as atividades da Secretaria de Estado da Saúde no âmbito regional e promover a articulação intersetorial, com os municípios e organismos da sociedade civil.

O decreto $\mathrm{n}^{\circ}$ 64.994, de 28 de maio de 2020, no Artigo 2ª , institui o Plano São Paulo, resultado da atuação coordenada do Estado com os Municípios paulistas, e por recomendação do Centro de Contingência do Coronavírus e do Centro de Vigilância Epidemiológica, ambos da Secretaria da Saúde, com o objetivo de implementar e avaliar ações e medidas estratégicas de enfrentamento à pandemia.

Para realização desses objetivos, as condições epidemiológicas e estruturais no Estado são mensuradas pela evolução do Covid-19 e da capacidade de respostas do sistema de saúde. Para medição da evolução do vírus é considerado o número de casos confirmados da doença com a identificação do período epidêmico. A medição da capacidade de resposta do sistema de saúde considera as informações concedidas pela Central de Regulação de Ofertas e Serviços de Saúde (CROSS) e no Censo Covid-19 do Estado ${ }^{4}$.

As condições epidemiológicas e estruturais determinam a classificação de cada região dentro das quatro fases existentes: vermelha, laranja, amarela e verde. A classificação em uma das fases é resultado da combinação dos indicadores de taxa de ocupação de leitos de UTI exclusivas para pacientes com coronavírus, número de novas internações no mesmo período e número de óbitos. A partir dessa combinação, cada região é colocada em um dos níveis da escala de abertura econômica. A mudança de nível é feita ao final de um balanço de uma semana pelo secretário de saúde do Estado. Se uma região apresenta piora nos índices de ocupação de leitos, contaminação e mortes por Covid-19, ela cai de nível, só sendo possível nova mudança após duas semanas, condicionada à melhora dos indicadores.

Apesar disso, o Plano possibilita certa autonomia para que os prefeitos aumentem ou diminuam as restrições, de acordo com os limites postos pelo Estado. Tal autonomia se encontra nas fases laranja, amarela e verde, nas quais o atendimento presencial de serviços e atividades não essenciais retomam mediante protocolos de funcionamento e de higiene. Os serviços não essenciais podem ser flexibilizados, mediante justificativa técnica e científica, de acordo com a vulnerabilidade econômica e empregatícia de cada região. Os setores de transporte e de educação contam com faseamento próprio, que segue as orientações da Secretaria da Saúde.

${ }^{4}$ Disponível em: http://www.saude.sp.gov.br/ses/perfil/cidadao/homepage/outros-destaques/covid-19-plano-decontingencia-boletins-diarios-e-outras-informacoes. Acesso em: 04 de ago. de 2020. 
Como já mencionado, para início da retomada das atividades dos setores da economia, o Plano São Paulo utiliza como indicadores, as taxas de isolamento, redução dos números de novos casos e taxa de ocupação de leitos de UTI. Os números ideais propostos foram baseados nas experiências de outros países que decidiram adotar uma retomada gradativa. É necessário contabilizar uma taxa de isolamento social em cada região maior que $55 \%$, apresentar uma redução sustentada de novos casos por 14 dias e taxa de ocupação de leitos de UTI exclusivos para Covid-19 inferior a $60 \%$.

O decreto que institui o Plano São Paulo também é específico a respeito das medidas especiais para os estabelecimentos comerciais e prestadores de serviços: esses devem impedir aglomerações, devem adotar normas especiais visando à proteção de idosos, gestantes e pessoas com doenças crônicas ou imunodeprimidas, à luz das recomendações do Ministério da Saúde e da Secretaria de Estado da Saúde.

O Plano São Paulo de retomada da economia entrou em vigor no dia primeiro de junho de 2020 com a seguinte explicação do governador de São Paulo, João Dória: "a nova fase do enfrentamento à pandemia do novo coronavírus em São Paulo não é um relaxamento, mas sim um ajuste fino levando em conta as particularidades regionais [...], o governo paulista coletou dados técnicos que permitem a volta gradual e segura de atividades em cidades do Estado que tiverem redução consistente do número de casos e disponibilidade de leitos nos seus hospitais públicos e privados e estiverem respeitando distanciamento social, além da disseminação e uso obrigatório de máscaras" $" 5$.

\section{Análise dos planos}

Após a análise do Plano de Alagoas para retomada econômica, "Plano de Distanciamento Controlado", e da análise do "Plano São Paulo", nos cabe agora compará-los a partir do que os influenciou e também de seu conteúdo.

No Brasil houve uma grande divergência acerca de como seria feito o combate ao Covid19. O Governo Federal sugeriu o distanciamento social vertical, em que apenas os grupos de risco deveriam se manter isolados. Os governos estaduais e municipais optaram pelo distanciamento social horizontal, sendo o critério de que todos os grupos devem ser isolados. Alagoas e São Paulo optaram pela segunda opção de distanciamento social, no caso do primeiro Estado, seguido as sugestões do Consórcio Nordeste.

${ }^{5}$ Disponível em: https://www.youtube.com/watch?v=xzZU61LMF40. Acesso em: 03 ago. 2020. 
O Consórcio Nordeste teve suma importância para a atuação regional no combate à pandemia do Covid-19, tendo defendido na "Carta dos Governadores do Nordeste" as recomendações de base científica a favor da adoção de medidas preventivas rígidas e também se manifestando contra as declarações do Presidente Jair Bolsonaro, demonstrando cada vez mais um alinhamento e fortalecimento das relações intergovernamentais nordestinas. Cabe ainda ressaltar a criação de um Comitê Científico para o combate ao vírus, que orientou as medidas do estado de Alagoas, desde o isolamento social até o Plano de Distanciamento Controlado.

O Consórcio Nordeste, que fora criado em 2019 unindo os 9 Estados da região com o objetivo de alavancar o desenvolvimento de maneira integrada, tendo a possibilidade de implementação de políticas públicas em conjunto nas áreas da educação, segurança e outras. $\mathrm{O}$ grupo foi responsável pela criação de um Comitê Científico cujo trabalho seria de orientar os integrantes no combate ao Covid-19.

O Comitê Científico é integrado por pesquisadores e médicos representantes dos Estados Nordestinos, e trabalha no sentido de articular os Estados e regiões do Nordeste a partir de medidas baseadas no conhecimento. Cabe ressaltar ainda a criação do Projeto Mandacaru? uma plataforma de colaboração virtual que visa a coleta de informações sobre os casos, sobre o espalhamento do vírus na região e os trabalhos científicos acerca do vírus em todo o mundo. O Estado de Alagoas é representado no projeto a partir do professor da Universidade Federal de Alagoas (UFAL), Fábio Guedes. Devendo-se ressaltar que o Comitê Científico teve papel importante na formulação dos diversos decretos, também influenciando o plano de retomada econômica.

Diferente de Alagoas, o Estado de São Paulo não instituiu um comitê científico regional para orientar suas ações, mas possui o Comitê Administrativo Extraordinário Covid-19, que cuida das deliberações e demandas do setor de administração pública e do setor privado acerca das medidas de combate ao novo vírus. Cabe ainda ressaltar que o Estado conta com duas pastas na Secretaria de Saúde, que estão atuando diretamente no enfrentamento da Covid-19: o Centro de Contingência do Coronavírus e o Centro de Vigilância Epidemiológica.

Passemos a comparar os níveis de isolamento social, expansão do vírus, número de leitos especializados e a regionalização da quarentena nos dois estados.

${ }^{6}$ Disponível em: https://www.cnnbrasil.com.br/politica/2020/03/25/em-carta-governadores-do-nordeste-criticambolsonaro-e-defendem-priorizar-saude. Acesso em: 04 ago. 2020.

${ }^{7}$ Disponível em: https://www.comitecientifico-ne.com.br/mandacaru. Acesso em: 01 ago. 2020. 
Com o decreto do posto pelo governador Renan Filho, a quarentena e o isolamento social foram as primeiras medidas de combate à Covid-19. O Estado registrou índices baixos de isolamento social no momento de pico da situação epidemiológica (um pouco mais de 50\%), quando o recomendado pelo comitê científico do Consórcio Nordeste era uma taxa de no mínimo 70\%. A taxa mais alta de isolamento social registrada no Estado foi no dia 29 de março (60,2\%), quando eram contabilizados 17 infectados e nenhum óbito ${ }^{8}$.

No Estado de São Paulo, o Decreto que conta com a medida de quarentena e isolamento social foi publicado no dia 22 de março de 2020. A taxa recomendada de isolamento social deve ser maior que 55\%. O maior número que o Estado conseguiu atingir foi no mesmo dia 22 de março, com um índice de isolamento de 62,5\%,631 casos positivados para Covid-19 e 22 óbitos confirmados. Quatro meses depois do Decreto, foram registrados 483.982 casos confirmados e 21.606 óbitos, com taxa de isolamento social atingindo 48,5\%, inferior ao recomendado e com a curva epidemiológica ainda crescente, entretanto, a taxa de ocupação de leitos de UTI direcionadas apenas a pacientes com Covid-19 era de $66,1 \% 9$.

A respeito da situação epidemiológica de cada Estado, ambos registraram crescimento na taxa de contaminação e mortes por Covid-19. De acordo com o Painel Coronavírus do Governo Federal ${ }^{10}$, o Estado de Alagoas, de 27 de fevereiro até 26 de julho, foram registrados 55.376 casos positivados e 1.500 óbitos. No caso do Estado de São Paulo, os números são maiores, mostrando um crescimento nítido na curva dos gráficos: no mesmo intervalo de tempo, foram registrados 483.982 casos e 21.606 óbitos.

É importante especificar que a data início para o acúmulo de dados se deu no dia seguinte ao primeiro caso confirmado de infecção por Covid-19 no Brasil, 26 de fevereiro, na cidade de São Paulo.

Os dois planos possuem fases para delimitar as ações que cada gestor municipal poderá adotar. Ambos os Estados compreendem suas especificidades regionais e os critérios para divisão dos territórios de cada Estado seguiram a lógica de abrangência que os Departamentos Regionais de Saúde (DRS) e as Redes Regionais de Atenção à Saúde (RRAS) conseguem contemplar. Sendo assim, percebemos uma dinâmica de regionalização da quarentena, específica à demanda de cada território, sendo de caráter heterogêneo quando vista por uma perspectiva estadual.

8 Disponível em: https://cienciapolitica.org.br/index.php/noticias/2020/06/especial-abcp-acoes-alagoasenfrentamento-pandemia. Acesso em: 03 ago. 2020.

${ }^{9}$ Disponível em: https://www.saopaulo.sp.gov.br/coronavirus/quarentena/. Acesso em: 03 ago. 2020.

${ }^{10}$ Disponível em: https://covid.saude.gov.br/. Acesso em: 01 ago. 2020. 
Os indicadores que irão diagnosticar a situação epidemiológica de cada Estado são semelhantes em alguns pontos: no Plano São Paulo é preciso contabilizar uma taxa de isolamento social em cada região maior que 55\%, apresentar uma redução sustentada de novos casos por 14 dias e taxa de ocupação de leitos de UTI exclusivos para Covid-19 inferior a 60\%. No Plano de Distanciamento Controlado a proposta possui três eixos estratégicos, são esses: a capacidade hospitalar instalada (mensurada pela taxa de ocupação de leitos com respiradores, taxa de ocupação de leitos geral e quantidade de leitos com respiradores por 100 mil habitantes), a evolução epidemiológica (indicada pela quantidade de óbitos por semana e a taxa de letalidade) e a taxa de evolução do Covid-19 (medida entre a razão de casos ativos e casos recuperados). Assim, relacionando os números indicados em cada região, é feito o diagnóstico sobre cada território específico e qual é sua posição dentre as fases de cada plano e qual será seu nível flexibilização. 


\section{Imagem 1}

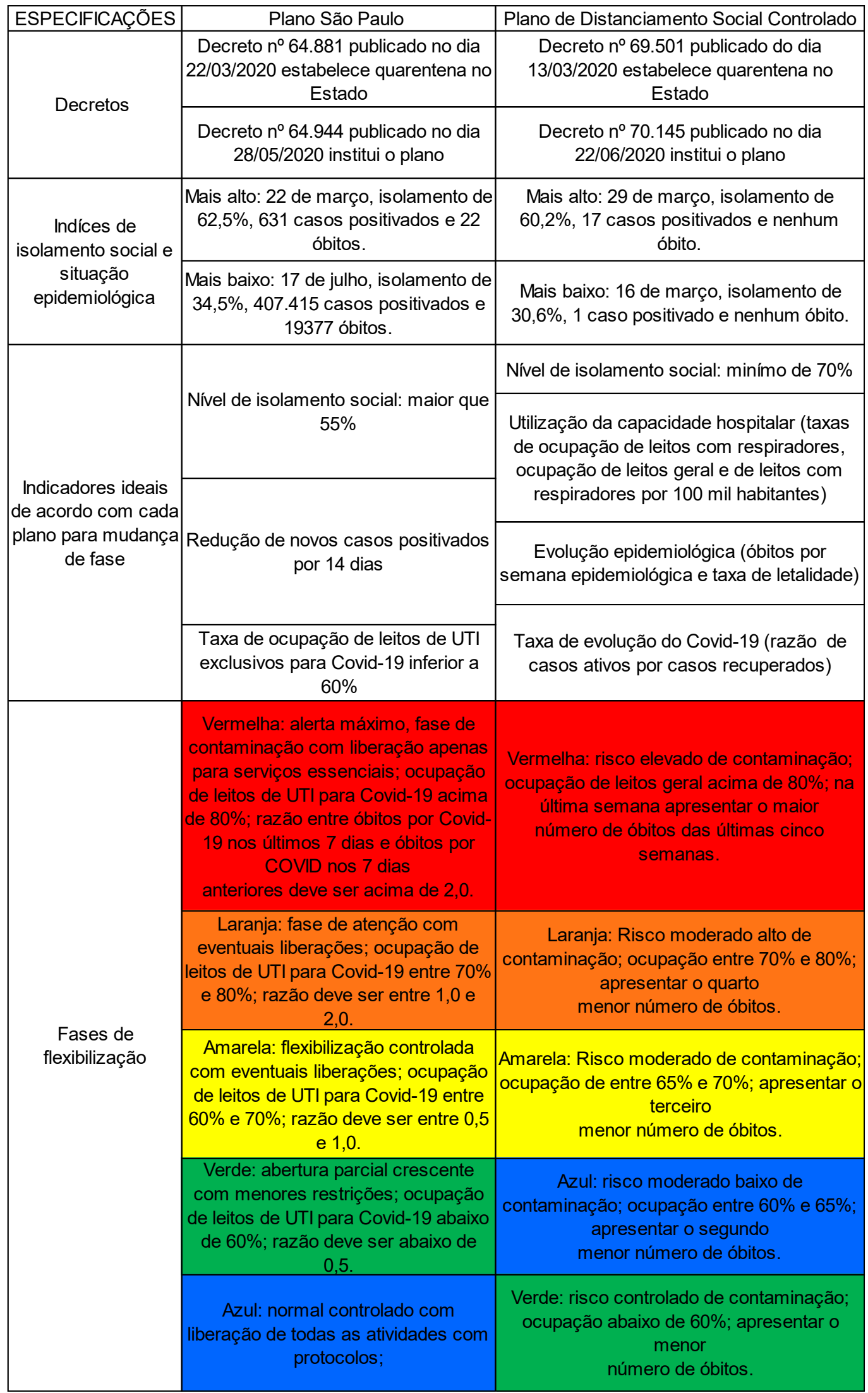

Fonte: Desenvolvido exclusivamente com dados obtidos no Plano de Distanciamento Controlado e Plano São Paulo 


\section{Considerações finais}

O Estado de Alagoas, apesar de ser um dos que mais demorou para apresentar avanço de casos da nova doença, teve uma resposta rápida dos seus governantes; por outro lado, houve a falta de contribuição por parte da população, que fez com que os índices de isolamento social fossem alguns dos mais baixos do país. Mesmo com a agilidade do governo, pautada em bases científicas, os casos cresceram no Estado, a partir do final de abril. Somente após três meses, em junho, foi observado o desafogamento nos hospitais. Isso, somado à pressão feita pelos diversos setores comerciais, fez com que fosse anunciado o plano de retomada no dia 22 do mesmo mês. Cabe ressaltar que ainda não foi observada queda no número de casos, o que pode significar a volta do aumento da ocupação de UTIs e mudança nos índices, com a abertura do comércio, como alertado pelo Consórcio Nordeste.

Com relação ao Estado de São Paulo, podemos notar que a reação governamental inicial à pandemia foi de certo modo ágil, pois foi tomada num estágio ainda precoce de disseminação. A capital abriu três hospitais de campanha, dois construídos pela prefeitura e um pelo Estado. O governo paulista ainda realizou repasses para os municípios com menos de 100 mil habitantes, financiando custeio, compra de insumos, montagem e operação de equipamentos, e criou o Conselho Municipalista entre Governo e Prefeituras para compactuar decisões.

Entretanto, no dia 22 de julho, o Estado de São Paulo registrou 16.777 casos confirmados de Covid-19, batendo um novo recorde (antes eram 12.244). Segundo o novo secretário estadual da Saúde, Jean Gorinchteyn ${ }^{11}$, tal resultado se deve ao aumento do número de testagens que estão sendo processadas. Com isso, o Estado totaliza 463.218 casos confirmados do novo coronavírus, com 299.647 pessoas recuperadas e 21.206 mortes. Há 5.416 pessoas internadas em UTIs de todo o Estado com casos confirmados ou suspeitos da doença, somando uma taxa de ocupação de leitos de UTI em torno de 66,5\%, enquanto na Grande São Paulo isso gira em torno de $64 \%$.

Houve também dificuldades relacionadas à falta de coordenação federativa: a ineficiente distribuição dos equipamentos de saúde e os impasses na negociação de medidas de compensação das perdas fiscais subnacionais. $\mathrm{O}$ decreto de quarentena partiu do executivo

${ }^{11}$ O ex-secretário de saúde, José Henrique Germann, deixou o cargo no dia 21 de julho devido a problemas de saúde no coração, ele já não participava mais das coletivas de imprensa diárias havia três semanas. Seu substituto é o infectologista Jean Gorinchteyn que trabalha nos hospitais Albert Einstein e São Camilo, e no Instituto de Infectologia Emilio Ribas. Gorinchteven é formado pela Universidade Mogi das Cruzes, é mestre em doenças infecciosas, doutorando em neurologia experimental pela Unifesp e com mais de 20 anos de atuação como médico e professor. Disponível em: https://g1.globo.com/sp/sao-paulo/noticia/2020/07/21/secretario-da-saude-de-saopaulo-germann-deixa-o-cargo-e-infectologista-do-emilio-ribas-assume-pasta.ghtml. Acesso em: 03 ago. 2020. 
estadual, uma vez que esta não foi decretada, até julho de 2020, pelo governo federal e nos termos da lei federal, o gestor local de saúde, autorizado pelo Ministério de Saúde, pode adotar a medida da quarentena.

AGRADECIMENTOS: agradecemos o apoio oferecido pelo Grupo de Estudo e Pesquisa Participação e Democracia (GEPPADE) e a Fundação de Amparo à Pesquisa do Estado de São Paulo que fomenta Igor Copoli Ramazzine.

\section{REFERÊNCIAS}

AGÊNCIA ESTADO. Entenda como será o plano de retomada das atividades anunciado em São Paulo. Correio Braziliense, 27 maio 2020. Disponível em: https://www.correiobraziliense.com.br/app/noticia/brasil/2020/05/27/internabrasil,858740/como-sera-o-plano-de-retomada-das-atividades-anunciado-em-sao-paulo.shtml. Acesso em: 22 jul. 2020.

ALAGOAS. A pandemia de Covid 19 e o Plano de distanciamento controlado. Estadão, 21 jul. 2020. Disponível em: https://politica.estadao.com.br/blogs/gestao-politica-esociedade/alagoas-a-pandemia-de-covid-19-e-o-plano-de-distanciamentocontroladoi/\#_ednref9. Acesso em: 21 jul. 2020.

ALAGOAS. Decreto n. 69.501, de 13 de março de 2020. Dispõe sobre as medidas para enfrentamento da emergência de saúde pública de importância internacional decorrente do COVID-19 (Coronavírus), e dá outras providências. Alagoas, 13 mar. 2020.Disponível em: http://www.procuradoria.al.gov.br/centro-de-estudos/boletim-informativo/legislacaoestadual/DECRETO\%20N-a6\%2069.501-\%20DE\%2013\%20DE\%20MARcO\%20DE\%202020.pdf/view?searchterm=. Acesso em: 21 jul. 2020.

ALAGOAS. Decreto n. 70.177, de 26 de junho de 2020. Dispõe sobre a matriz de risco e dá outras providências. Alagoas, 26 jun. 2020. Disponível em: https://www.legisweb.com.br/legislacao/?id=397617. Acesso em: 21 jul. 2020.

ALAGOAS. Decreto n. 70.178, de 30 de junho de 2020. Determina a classificação do estado de Alagoas conforme o Plano de Distanciamento Social Controlado, e dá outras providências. Alagoas, 30 jun. 2020. Disponível em: https://www.legisweb.com.br/legislacao/?id=397864. Acesso em: 21 jul. 2020.

ALAGOAS. Decreto $\mathbf{N}^{\mathbf{0}} \mathbf{7 0 . 1 4 5}$, de 22 de junho de 2020. Institui o Plano de Distanciamento Social Controlado no âmbito do estado de Alagoas, e dá outras providências. Disponível em: http://www.imprensaoficialal.com.br/wp-content/uploads/2020/06/DOEAL-22_06_2020SUPLEMENTO.pdf. Acesso em: 20 jul. 2020.

ARRETCHE, M. Políticas Sociais no Brasil: descentralização em um estado federativo. Revista Brasileira de Ciências Sociais, São Paulo, v. 14 n. 40, jun. 1999. 
CIÊNCIA. Consórcio Nordeste cria Comitê Científico para orientar região no combate ao coronavírus. Rádio Jornal Pernambuco, 17 abr. 2020. Disponível em:

https://radiojornal.ne10.uol.com.br/noticia/2020/04/17/consorcio-nordeste-cria-comitecientifico-para-orientar-regiao-no-combate-ao-coronavirus-187256. Acesso em: 23 jul. 2020.

CNN BRASIL. Em carta governadores do Nordeste criticam Bolsonaro e defendem priorizar saúde. 25 mar. 2020. Disponível em:

https://www.cnnbrasil.com.br/politica/2020/03/25/em-carta-governadores-do-nordestecriticam-bolsonaro-e-defendem-priorizar-saude. Acesso em: 04 ago. 2020.

CRUZ, E. P. SP tem novo recorde diário de casos confirmados do novo coronavírus. Agência Brasil, 22 jul. 2020. Disponível em: https://agenciabrasil.ebc.com.br/saude/noticia/202006/saiba-como-estados-brasileiros-est $\% \mathrm{C} 3 \% \mathrm{~A} 30$-retomando-a-atividade-economica. Acesso em: 25 jul. 2020.

ELAZAR, D. Self-Rule/Shared Rule: federal solutions to the middle east conflict. Lanham: University Press of America, 1984.

GONZAGA, T. Ufal participa de comitê que auxilia governadores do NE no combate à covid19. Universidade Federal de Alagoas, 8 maio 2020. Disponível em:

https:/ufal.br/ufal/noticias/2020/5/ufal-participa-de-comite-que-auxilia-governadores-donordeste-no-combate-a-covid-19. Acesso em 23 jul. 2020.

INLOCO. Mapa brasileiro da COVID-19. Disponível em:

https://mapabrasileirodacovid.inloco.com.br/pt/. Acesso em: 23 jul. 2020.

JOÃO DORIA APRESENTA plano de retomada para o Estado de São Paulo. 27 mar. 2020. 1 vídeo (134 min). Publicado pelo Canal UOL. Disponível em:

https://www.youtube.com/watch?v=xzZU61LMF40. Acesso em: 03 ago. 2020.

MAIA, S. Consórcio Nordeste: entenda o que é a iniciativa. Instituto para Reforma das Relações entre Estado e Empresa. Disponível em: https://iree.org.br/consorcio-nordesteentenda-o-que-e-a-iniciativa/. Acesso em: 23 jul. 2020.

NEXO JORNAL. Como os governos estaduais lidam com a pandemia. 10 maio 2020. Disponível em: https://www.nexojornal.com.br/especial/2020/05/10/Como-os-governosestaduais-lidam-com-a-pandemia. Acesso em: 22 jul. 2020.

RIKER, W. Federalism: origin, operation, significance. Little Brown, 1964.

SANTANA, L.; DO NASCIMENTO, E.; DE LIMA ANDRADE, E. Especial ABC: As ações de Alagoas no enfrentamento à pandemia. Associação Brasileira de Ciência Política. 11 de junho de 2020. Disponível em:

https://cienciapolitica.org.br/index.php/noticias/2020/06/especial-abcp-acoes-alagoasenfrentamento-pandemia. Acesso em: 21 jul. 2020.

SÃO PAULO. Decreto n. 64.879, de 20 de março de 2020. Reconhece o estado de calamidade pública, decorrente da pandemia do COVID-19, que atinge o Estado de São Paulo, e dá providências correlatas. São Paulo, 23 mar. 2020. Disponível em: 
http://dobuscadireta.imprensaoficial.com.br/default.aspx?DataPublicacao $=20200323 \&$ Cadern $\mathrm{o}=$ DOE-I\&NumeroPagina=1. Acesso em: 21 jul. 2020.

SÃO PAULO. Decreto n. 64.881, de 22 de março de 2020. Decreta quarentena no Estado de São Paulo, no contexto da pandemia do COVID-19 (Novo Coronavírus), e dá providências complementares. São Paulo, 23 mar. 2020. Disponível em:

http://dobuscadireta.imprensaoficial.com.br/default.aspx?DataPublicacao $=20200323 \&$ Cadern $\mathrm{o}=$ DOE-I\&NumeroPagina=1. Acesso em: 21 jul. 2020.

SÃO PAULO. Decreto n. 64.882, de 22 de março de 2020. Dá nova redação ao artigo $2^{\circ}$ do Decreto ${ }^{0}$ 63.915, de 12 de dezembro de 2018. São Paulo, 23 mar. 2020. Disponível em: http://dobuscadireta.imprensaoficial.com.br/default.aspx?DataPublicacao $=20200323 \&$ Cadern $\mathrm{o}=$ DOE-I\&NumeroPagina=1. Acesso em: 21 jul. 2020.

SÃO PAULO. Decreto n. 64.994, de 28 de maio de 2020. Dispõe sobre a medida de quarentena de que trata o Decreto ${ }^{0} 64.881$, de 22 de março de 2020, institui o Plano São Paulo e dá outras providências complementares. São Paulo, 29 maio 2020. Disponível em: $\mathrm{http} / /$ diariooficial.imprensaoficial.com.br/nav_v5/index.asp?c $=4 \& \mathrm{e}=20200529 \& \mathrm{p}=1$. Acesso em: 21 jul. 2020.

SÃO PAULO. Plano São Paulo. 2020. Disponível

em: https://www.saopaulo.sp.gov.br/planosp/. Acesso em: 21 jul. 2020.

SÃO PAULO. Secretária de estado da saúde. Plano de contingência. Boletins diários. 2020. Disponível em: http://www.saude.sp.gov.br/ses/perfil/cidadao/homepage/outros-

destaques/covid-19-plano-de-contingencia-boletins-diarios-e-outras-informacoes. Acesso em: 04 ago. 2020.

SÃO PAULO. SP contra o novo coronavírus: tudo sobre a quarentena. São Paulo. 2020. Disponível em: https://www.saopaulo.sp.gov.br/coronavirus/quarentena/. Acesso em: 20 jul. 2020.

SOUZA, C. Coordenação, uniformidade e autonomia na formulação de políticas públicas: experiências federativas no cenário internacional e nacional. Cadernos de Saúde Pública, Rio de Janeiro, v. 35, supl. 2, 2019.

TORRES, J. Boletim 29/03/2020: Alagoas tem 17 casos confirmados para Covid-19. Secretaria de Estado da Saúde de Alagoas. 29 de março de 2020. Disponível em: https://www.saude.al.gov.br/boletim-29-03-2020-alagoas-tem-17-casos-confirmados-paracovid-19/. Acesso em: 24 jul. 2020.

TRALLI, C. Secretário da Saúde de São Paulo, Germann, deixa o cargo e infectologista do Emílio Ribas assume pasta. G1, 21 jun. 2020. Disponível em: https://g1.globo.com/sp/saopaulo/noticia/2020/07/21/secretario-da-saude-de-sao-paulo-germann-deixa-o-cargo-einfectologista-do-emilio-ribas-assume-pasta.ghtml. Acesso em: 04 ago. 2020.

VALENTE, J.; SOUZA, L.; TOKARNIA, M. Saiba como estados estão retomando as atividades econômicas no país. Agência Brasil, 22 de junho de 2020. Disponível em: https://agenciabrasil.ebc.com.br/saude/noticia/2020-06/saiba-como-estados-brasileirosest\%C3\%A3o-retomando-a-atividade-economica. Acesso em: 24 jul. 2020. 


\section{Como referenciar este articulo}

ANDRADE, R. G. E.; RAMAZZINE, I. C.; COLOMBO, L. A. O federalismo brasileiro e os planos de abertura econômica do estado de Alagoas e São Paulo para a pandemia da COVID19. Rev. Sem Aspas, Araraquara, v. 9, n. 1, p. 61-79, jan./jun., 2020. e-ISSN: 2358-4238. DOI: https://doi.org/10.29373/sas.v9i1.14038

Submetido em: 10/06/2020

Revisões requeridas: $05 / 08 / 2020$

Aprovado em: $30 / 08 / 2020$

Publicado em: 30/09/2020 